\title{
Gold Aerogel Monoliths with Tunable Ultra-low Densities
}

Fang Qian*, Alyssa Troksa, Tyler M. Fears, Michael H. Nielsen, Art J. Nelson, Theodore F.

Baumann, Sergei O. Kucheyev, T. Yong Han, Michael Bagge-Hansen

Physical and Life Sciences Directorate, Lawrence Livermore National Laboratory, Livermore, California 94550 

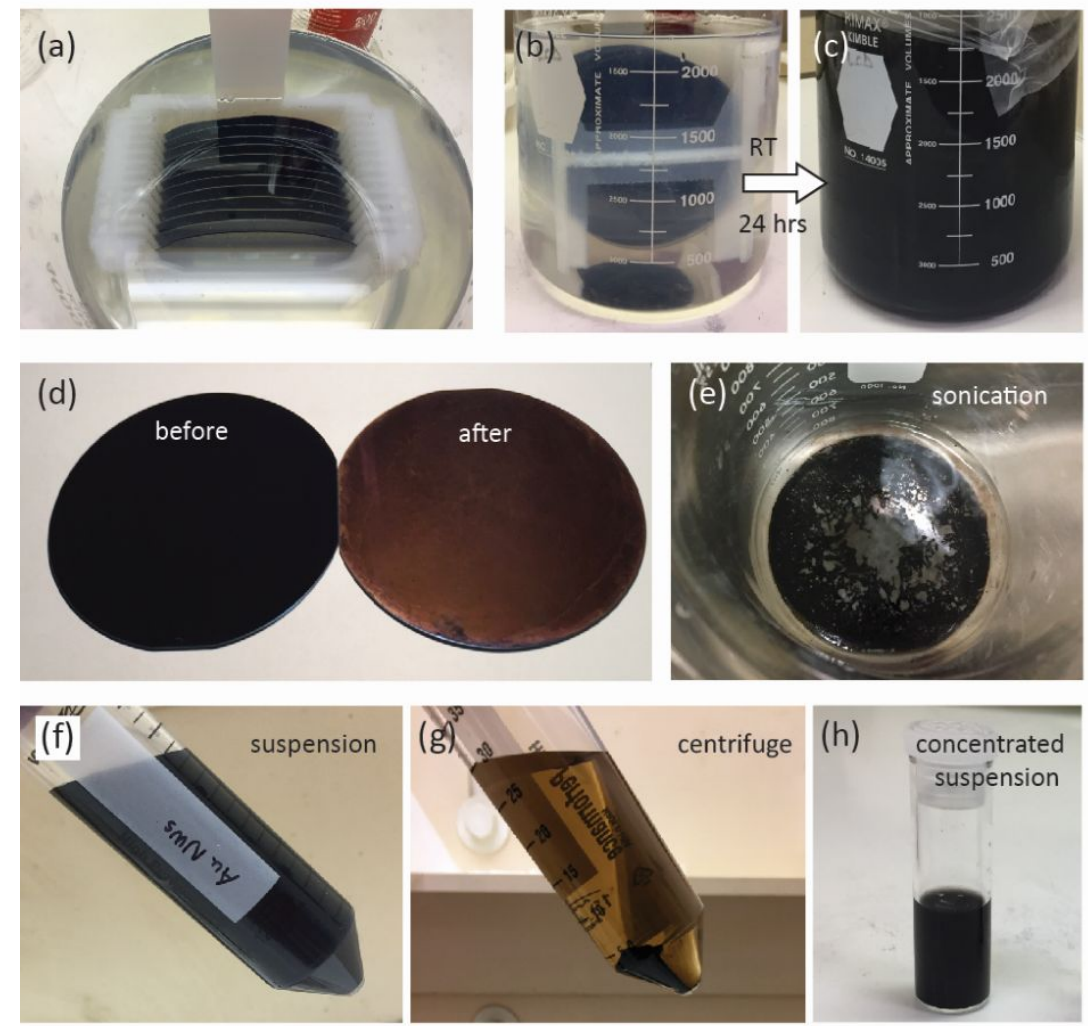

Figure S1. Procedure of the nanowire growth and the preparation of nanowire suspension.
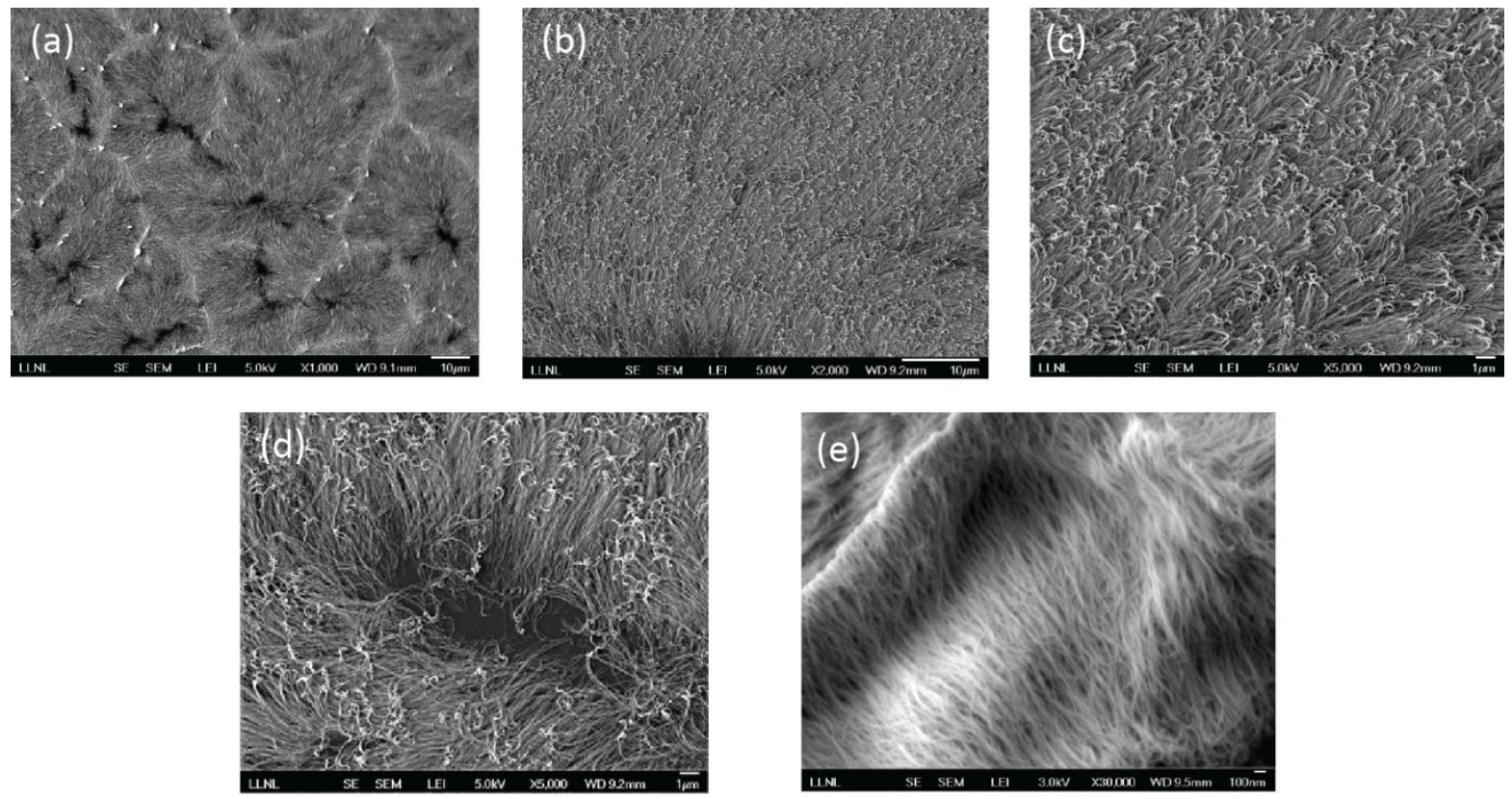

Figure S2. SEM images of AuNWs grown on a silicon wafer at different magnifications. 

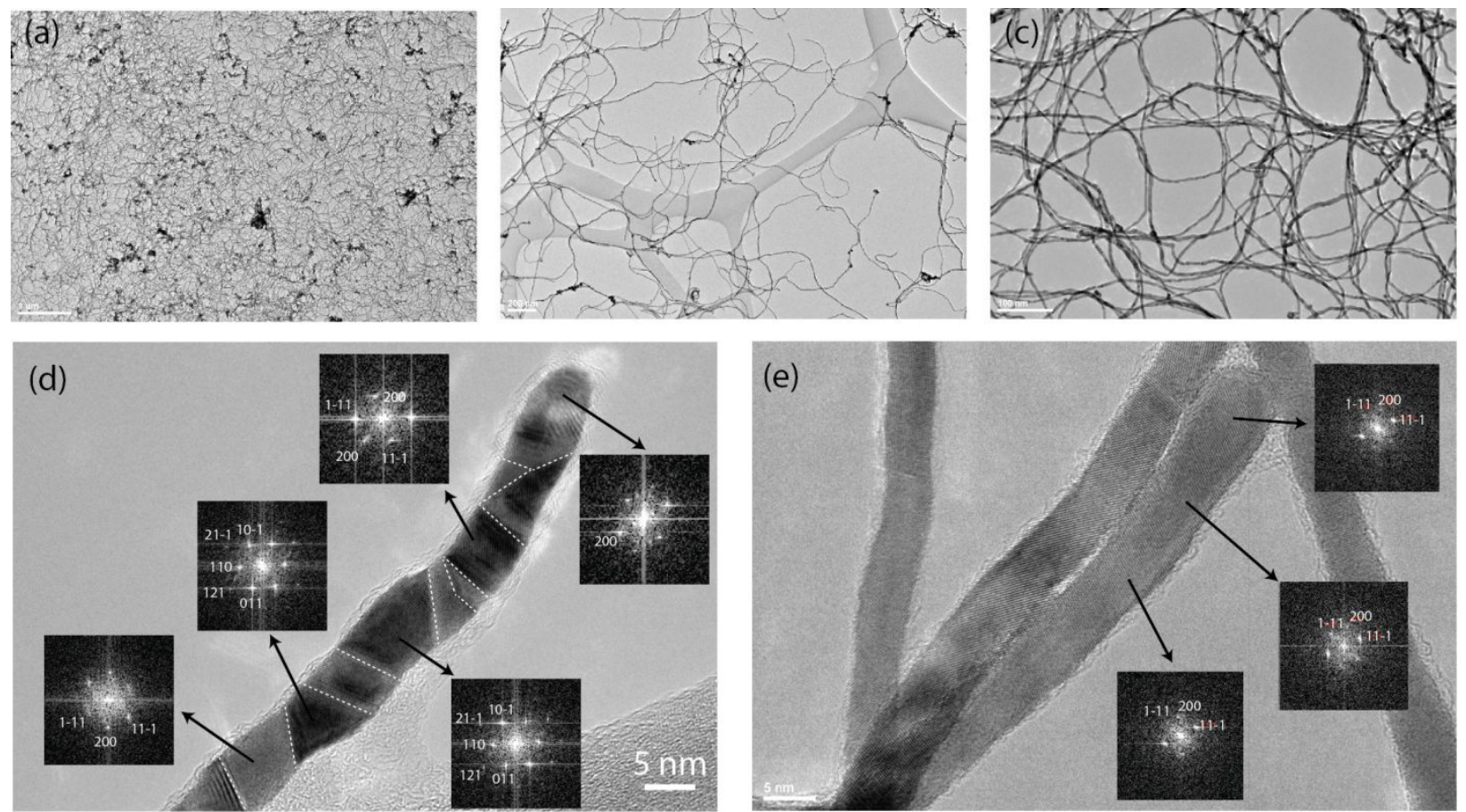

Figure S3. TEM data of AuNWs. (a-c) Low-magnification images of AuNWs sonicated off the substrate. $(\mathrm{d}, \mathrm{e})$ High-magnification images and corresponding electron diffraction patterns of nanowires with $\mathrm{BCB}$ tetrahelix twin-crystal structures or single-crystal structures.
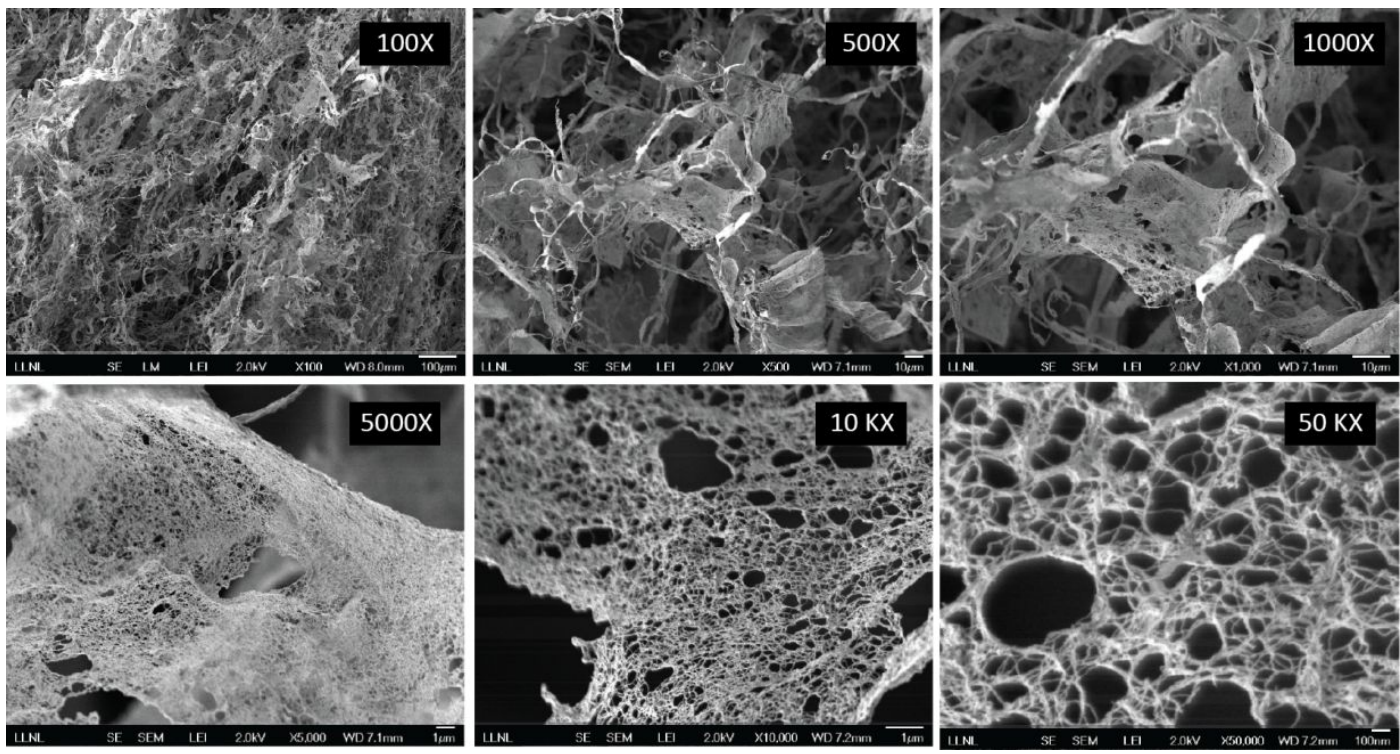

Figure S4. SEM images of an AuNW aerogel made with water solvent at different magnifications. 

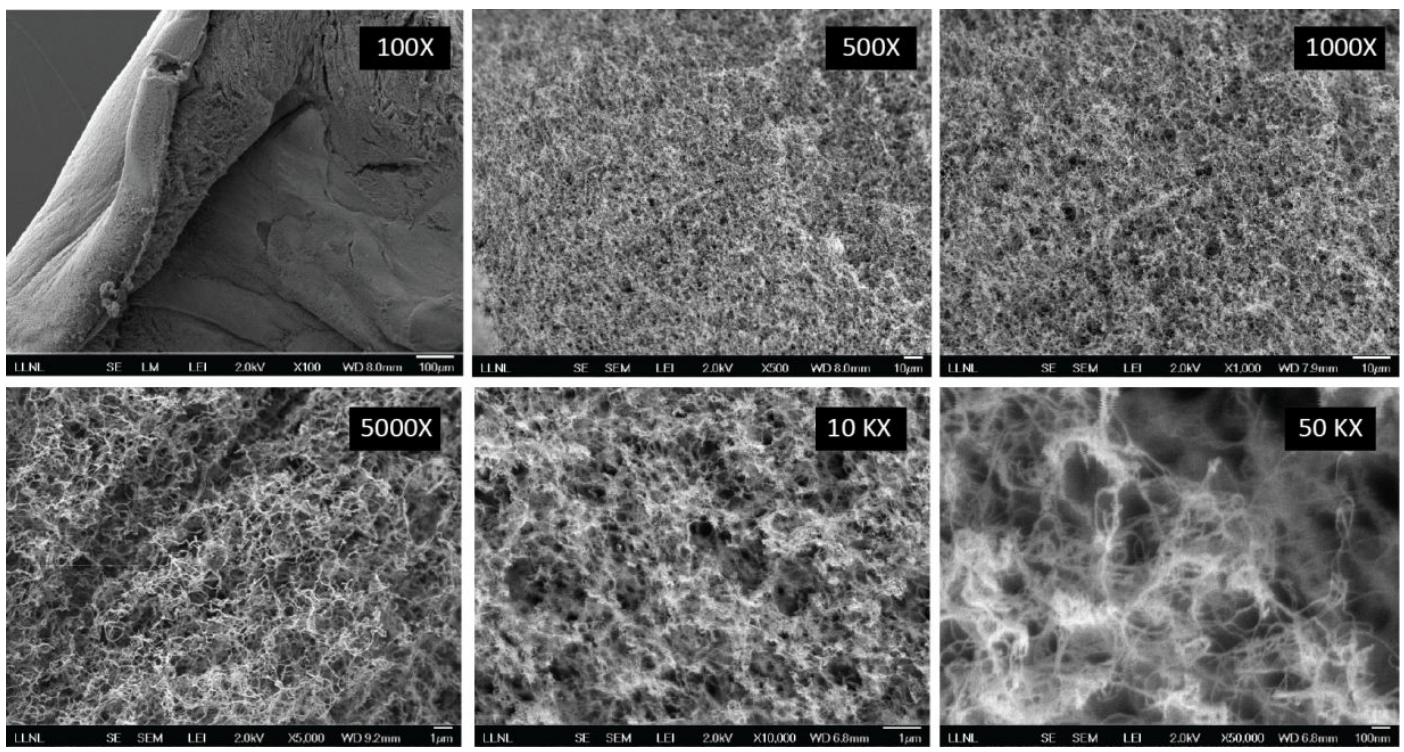

Figure S5. SEM images of AuNW aerogel made with 18\% TBA eutectic solvent at difference magnifications.

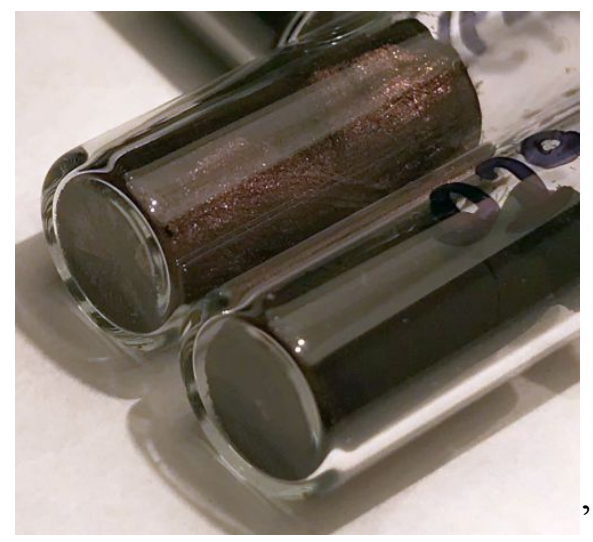

Figure S5. A photograph taken from (top) a water-based AuNW aerogel and (bottom) a eutectic solvent-based AuNW aerogel. 


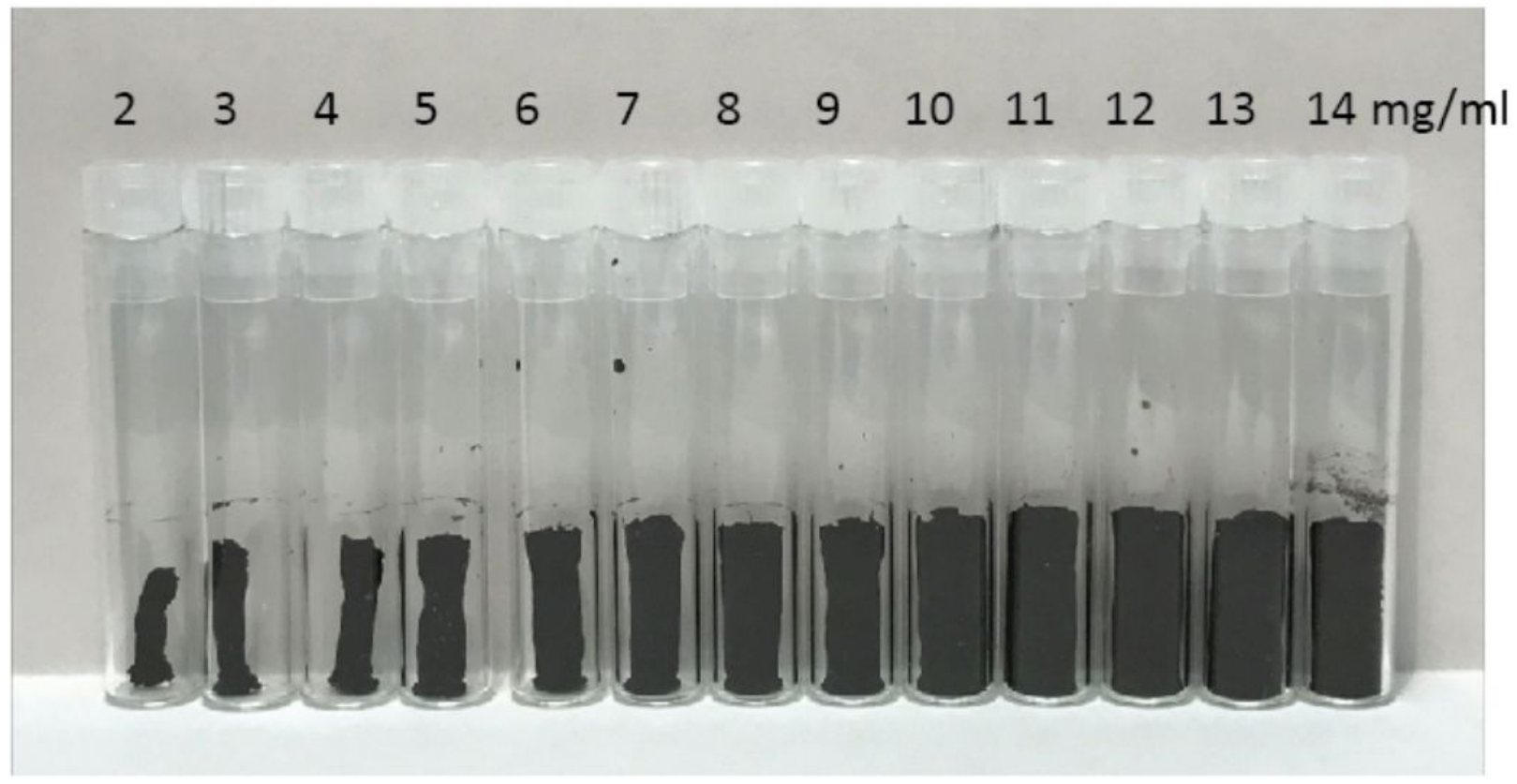

Figure S6. Gold nanowire aerogels made with the eutectic solvent (18wt $\%$ TBA in water solution), using nanowire suspension with nanowire concentration increasing from 2 to 14 $\mathrm{mg} / \mathrm{ml}$. Note the volume shrinkage of aerogels was negligible above a critical density of 12 $\mathrm{mg} / \mathrm{ml}$. 